\title{
Rediscovering the patellofemoral joint
}

\author{
David Dejour · Elizabeth Arendt $\cdot$ Stefano Zaffagnini
}

Published online: 13 August 2014

(C) Springer-Verlag Berlin Heidelberg 2014

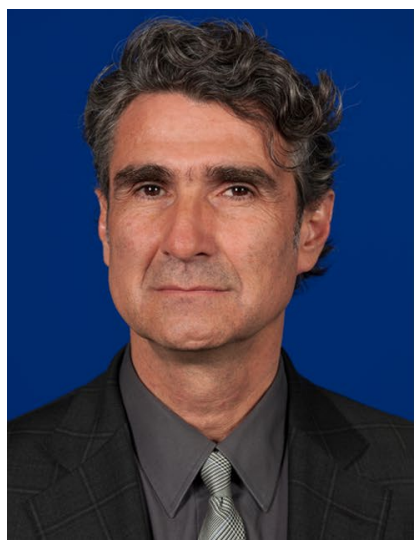

David Dejour

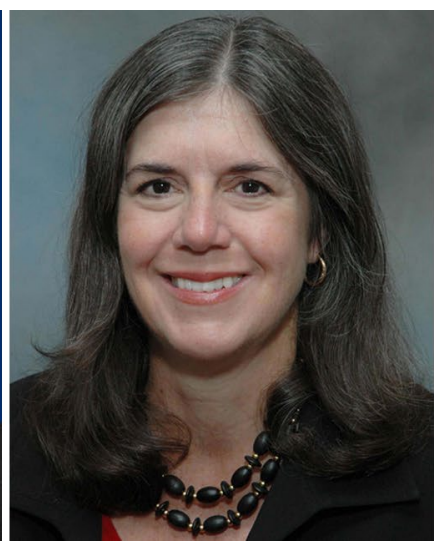

Elizabeth Arendt

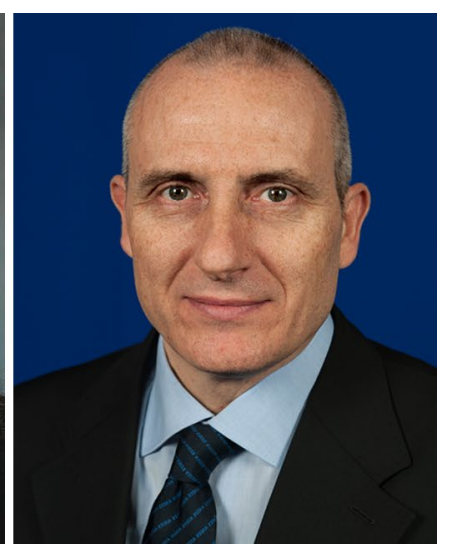

Stefano Zaffagnini
KSSTA is happy to provide a special issue on the patellofemoral (PF) disorders. PF disorders span a number of common clinical presentations including PF pain, PF instability and injury, and PF arthritis. These disorders are often controversial in terms of diagnosis, imaging, and treatment; indeed the last decade has seen an explosion of new knowledge and insight into this field, including emerging techniques for diagnosis and treatment. What are the patient outcomes in 2014 using this emergent data? We have done a selection of peer-reviewed articles, which will present

D. Dejour

Lyon Ortho Clinic, Lyon, France

\section{E. Arendt}

Department of Orthopaedic Surgery, University of Minnesota,

Minneapolis, MN, USA

\section{S. Zaffagnini $(\bowtie)$}

Istituto Ortopedico Rizzoli, Bologna, Italy

e-mail: stefano.zaffagnini@unibo.it fresh viewpoints and hopefully will be infused into your daily clinical practice in this field.

Within this special edition you will find articles on the painful anterior knee, which is a common clinical presentation in knee clinics. Petersen et al. [21] describes the patellar painful syndrome while Werner et al. [28] outlines contemporary non-operative management algorithms. Rathleff et al. [22] explains the importance of foot position in sport to prevent pain. Sanchis-Alfonso et al. [24] delves into the patient psyche and examines the mental attitude or daily mood and its potential influence on the PF pain. He proposes a holistic view of this difficult clinical entity [7].

Patellar dislocation is a different category. Balcarek et al. [2] and Sillampää et al. [27] give insight into predicting the recurrent dislocator after primary lateral patella dislocation. Arendt et al. [1] gives us a very uncommon differential diagnosis, often missed in clinical practice.

The objective analysis of the PF joint remains a cornerstone of diagnoses. Standard radiographs, stress radiographs, MRI, and 3D analyses are joined by the gait pattern 
and the global patient overview as keys to determinants of clinical analysis to select the appropriate treatment [9, 12]. Several articles probe deeper into established objective imaging instability factors. The measurement of the TTTG in the presence of trochlea dysplasia and its validity is analysed [5, 8]. Seitlinger et al. [25] introduces the notion of flexion/extension in measuring Q-vector offset. Standard radiographs should not be forgotten; Magnussen et al. [15], explains different ways to quantify patella alta, and Nord et al. [19] examines radiographic pitfalls in obtaining an appropriate axial view. Niimoto et al. [18] describes the use of stress radiograph to rate the efficiency of his lateral release. Latt et al. [14] describes the use of a cadaveric model trochlear dysplasia.

After a true dislocation, knowledge of damaged structures is helpful for both surgical and conservative management. How does damage to the cartilage alter our management algorithms? When is it necessary to treat? When is it detrimental? What are the options? Is the patellar damage equivalent to the trochlear damage; should they be treated the same way? Siebold et al. [26] and Meyerkort et al. [17] give some results about $\mathrm{ACI}$ and MACI in PF joint.

What are the surgical options for "objective patellar dislocation" group? MPFL reconstruction is a cornerstone of present day surgical management. The reader will find articles on varied techniques, graft sources, and fixation options [3, 29]. Feller et al. [11] explores the necessity to associate a bony procedure to the isolated MPFL reconstruction. These associated procedures could be tibial tubercle osteotomies for patella alta or excessive Q-vector, but also include rotational osteotomies as describes by Hinterwimmer et al. [13], or trochleoplasties, with an arthroscopic technique described by Blønd et al. [4]. Ntagiopoulos and Dejour [20] give us current concepts in trochleoplasty and its history over time.

After surgery, who is able to go back to sport activities? What are the outcomes of this surgery? Enderlein et al. [10] and Menetrey et al. [16] present results on outcomes and return to sport activities.

When arthritis presents in this joint, patellofemoral arthroplasty (PFA) is an option. Knowledge of PF anatomy and contemporary PFA design should aid in accomplishing the perfect surgical outcome [23]. Review of early outcomes help to select the ideal candidate for this surgical procedure [6].

These questions and concepts will be discussed and explored in this special edition. All articles have been peer reviewed, with selection among the numerous articles submitted to KSSTA.

We enjoyed assembling these diverse articles, all with a common theme of augmenting current PF knowledge. We hope PF clinicians and scientists find some interesting information and inspirations for future research reading this special edition.

\section{References}

1. Arendt EA, Fontboté CA, Rohr SR (2014) Displacing lateral meniscus masquerading as patella dislocation. Knee Surg Sports Traumatol Arthrosc. doi:10.1007/s00167-013-2729-z

2. Balcarek P, Oberthür S, Hopfensitz S, Frosch S, Walde TA, Wachowski MM, Schüttrumpf JP, Stürmer KM (2014) Which patellae are likely to redislocate? Knee Surg Sports Traumatol Arthrosc. doi:10.1007/s00167-013-2650-5

3. Berruto M, Ferrua P, Uboldi F, Usellini E, Gala L, Tassi A, Marelli B (2014) Medial patellofemoral ligament reconstruction with bioactive synthetic ligament is an option. A 3-year followup study. Knee Surg Sports Traumatol Arthrosc. doi:10.1007/ s00167-014-2970-0

4. Blønd L, Haugegaard M (2014) Combined arthroscopic deepening trochleoplasty and reconstruction of the medial patellofemoral ligament for patients with recurrent patella dislocation and trochlear dysplasia. Knee Surg Sports Traumatol Arthrosc. doi:10.1007/s00167-013-2422-2

5. Caplan N, Lees D, Newby M, Ewen A, Jackson R, St Clair Gibson A, Kader D (2014) Is tibial tuberosity-trochlear groove distance an appropriate measure for the identification of knees with patellar instability? Knee Surg Sports Traumatol Arthrosc. doi:10.1007/s00167-014-2954-0

6. Dahm D, Kalisvaart MM, Stuart MJ, Slettedahl SW (2014) Patellofemoral arthroplasty: outcomes and factors associated with early progression of tibiofemoral arthritis. Knee Surg Sports Traumatol Arthrosc. doi:10.1007/s00167-014-3202-3

7. Doménech J, Sanchis-Alfonso V, Espejo B (2014) Changes in catastrophizing and kinesiophobia are predictive of changes in disability and pain after treatment in patients with anterior knee pain. Knee Surg Sports Traumatol Arthrosc. doi:10.1007/ s00167-014-2968-7

8. Dornacher D, Reichel H, Lippacher S (2014) Measurement of tibial tuberosity-trochlear groove distance: evaluation of inter- and intraobserver correlation dependent on the severity of trochlear dysplasia. Knee Surg Sports Traumatol Arthrosc. doi:10.1007/ s00167-014-3083-5

9. Elias JJ, Carrino JA, Saranathan A, Guseila LM, Tanaka MJ, Cosgarea AJ (2014) Variations in kinematics and function following patellar stabilization including tibial tuberosity realignment. Knee Surg Sports Traumatol Arthrosc. doi:10.1007/s00167-014-2905-9

10. Enderlein D, Nielsen T, Christiansen SE, Faunø P, Lind M (2014) Clinical outcome after reconstruction of the medial patellofemoral ligament in patients with recurrent patella instability. Knee Surg Sports Traumatol Arthrosc. doi:10.1007/s00167-014-3164-5

11. Feller JA, Richmond AK, Wasiak J (2014) Medial patellofemoral ligament reconstruction as an isolated or combined procedure for recurrent patellar instability. Knee Surg Sports Traumatol Arthrosc. doi:10.1007/s00167-014-3132-0

12. Hasler RM, Gal I, Biedert RM (2014) Landmarks of the normal adult human trochlea based on axial MRI measurements: a cross-sectional study. Knee Surg Sports Traumatol Arthrosc. doi:10.1007/s00167-014-3152-9

13. Hinterwimmer S, Minzlaff P, Saier T, Niemeyer P, Imhoff AB, Feucht MJ (2014) Biplanar supracondylar femoral derotation osteotomy for patellofemoral malalignment: the anterior closed-wedge technique. Knee Surg Sports Traumatol Arthrosc. doi:10.1007/s00167-014-2993-6 
14. Latt LD, Christopher M, Nicolini A, Burk DR, Dezfuli B, Serack BJ, Fithian DC (2014) A validated cadaveric model of trochlear dysplasia. Knee Surg Sports Traumatol Arthrosc. doi:10.1007/ s00167-014-3033-2

15. Magnussen RA, De Simone V, Lustig S, Neyret P, Flanigan DC (2014) Treatment of patella alta in patients with episodic patellar dislocation: a systematic review. Knee Surg Sports Traumatol Arthrosc. doi:10.1007/s00167-013-2445-8

16. Menetrey J, Putman S, Gard S (2014) Return to sport after patellar dislocation or after surgery for patellofemoral instability. Knee Surg Sports Traumatol Arthrosc. doi:10.1007/s00167-014-3172-5

17. Meyerkort D, Ebert JR, Ackland TR, Robertson WB, Fallon M, Zheng MH, Wood DJ (2014) Matrix-induced autologous chondrocyte implantation (MACI) for chondral defects in the patellofemoral joint. Knee Surg Sports Traumatol Arthrosc. doi:10.1007/s00167-014-3046-x

18. Niimoto T, Deie M, Adachi N, Usman MA, Ochi M (2014) Quantitative stress radiography of the patella and evaluation of patellar laxity before and after lateral release for recurrent dislocation patella. Knee Surg Sports Traumatol Arthrosc. doi:10.1007/ s00167-014-2930-8

19. Nord A, Agel J, Arendt EA (2014) Axial knee radiographs: consistency across clinic sites. Knee Surg Sports Traumatol Arthrosc. doi:10.1007/s00167-014-2982-9

20. Ntagiopoulos PG, Dejour D (2014) Current concepts on trochleoplasty procedures for the surgical treatment of trochlear dysplasia. Knee Surg Sports Traumatol Arthrosc. doi:10.1007/ s00167-014-3013-6

21. Petersen W, Ellermann A, Gösele-Koppenburg A, Best R, Rembitzki IV, Brüggemann GP, Liebau C (2014) Patellofemoral pain syndrome. Knee Surg Sports Traumatol Arthrosc. doi:10.1007/ s00167-013-2759-6

22. Rathleff MS, Richter C, Brushøj C, Bencke J, Bandholm T, Hölmich P, Thorborg K (2014) Increased medial foot loading during drop jump in subjects with patellofemoral pain. Knee Surg Sports Traumatol Arthrosc. doi:10.1007/s00167-014-2943-3

23. Saffarini M, Ntagiopoulos PG, Demey G, Le Negaret B, Dejour DH (2014) Evidence of trochlear dysplasia in patellofemoral arthroplasty designs. Knee Surg Sports Traumatol Arthrosc. doi:10.1007/s00167-014-2967-8

24. Sanchis-Alfonso V (2014) Holistic approach to understanding anterior knee pain. Knee Surg Sports Traumatol Arthrosc, Clinical implications. doi:10.1007/s00167-014-3011-8

25. Seitlinger G, Scheurecker G, Hogler R, Labey L, Innocenti B, Hofmann $S$ (2014) The position of the tibia tubercle in $0^{\circ}-90^{\circ}$ flexion-Comparing patients with patella dislocation to healthy volunteers. Knee Surg Sports Traumatol Arthrosc. doi:10.1007/ s00167-014-3173-4

26. Siebold R, Karidakis G, Fernandez F (2014) Clinical outcome after medial patellofemoral ligament reconstruction and autologous chondrocyte implantation following recurrent patella dislocation. Knee Surg Sports Traumatol Arthrosc. doi:10.1007/ s00167-014-3196-x

27. Sillampää PJ, Salonen E, Pihlajamaki H, Maenpaa H (2014) Medial patellofemoral ligament avulsion injury at the patella: classification and clinical outcome. Knee Surg Sports Traumatol Arthrosc. doi:10.1007/s00167-014-3174-3

28. Werner S (2014) Anterior knee pain: an update of physical therapy. Knee Surg Sports Traumatol Arthrosc. doi:10.1007/ s00167-014-3150-y

29. Zaffagnini S, Marcheggiani Muccioli GM, Grassi A, Bonanzinga T, Marcacci M (2014) Minimally invasive medial patellofemoral ligament reconstruction with fascia lata allograft: surgical technique. Knee Surg Sports Traumatol Arthrosc. doi:10.1007/ s00167-014-2940-6 